\title{
Morphophysiological Characteristics of Soil Microscopic Fungi Belonging to Forest-Park Zone, to Lawn near the Roadway of Leninsky District, Grozny
}

\section{A M Dokhtukaeva, L G Molochaeva, Ya S Usaeva, F M Turlova, M M Arsanova, and A L Elderkhanova}

Department of cell biology, morphology and micro-biology, Chechen State University, Grozny, Russia

\section{Abstract}

The urgency of studying mold fungi is due to the fact that in recent years there has been a steady increase in the incidence of invasive mycoses among immunocompromised patients. In most cases, hospital mycotic infections caused by mold fungi are caused by Aspergillus spp., mainly A. fumigatus, A. flavus, A. niger. In analyzing the morphological and physiological characteristics of the mold fungi cells, micromycetes were identified,

Corresponding Author:

A M Dokhtukaeva

kurumova71@mail.ru

Received: 25 October 2019

Accepted: 15 November 2019

Published: 25 November 2019

Publishing services provided by Knowledge E

(c) A M Dokhtukaeva et al. This article is distributed under the terms of the Creative Commons Attribution License, which permits unrestricted use and redistribution provided that the original author and source are credited.

Selection and Peer-review under the responsibility of the AgroSMART 2019 Conference Committee. the generic affiliation was determined, and a comparative characteristic of the growth of fungi from the lawn near the roadway with mold fungi in the forest-park zone was carried out.

Keywords: mold, fungi, growth, micromycetes, morphology, characteristic, soil.

\section{Introduction}

One of the negative problems of our time is the global chemical pollution of biosphere, which gives a rise to well-founded concerns about a possible disturbance of the ecological balance in certain ecosystems $[1,2,7]$. Of particular danger there are synthetic compounds appearing in nature/environment as a result of human activities [3]. An important place among them is occupied by chemical means of protecting plants and animals - pesticides, one of which is the fungicide cartocide. Cartocide is a drug designed to combat fungal diseases of vegetables, fruits and berries and vineyards. It is also recommended to combat rot when storing vegetables. The active ingredient of the drug is tricaptolactam copper (II), dichloride, monohydrate. The generalized formula of substance is $\mathrm{C}_{18} \mathrm{H}_{35} \mathrm{Cl}_{2} \mathrm{CuN}_{3} \mathrm{O}_{4}$. Molecular weight - 492.0 It is a green crystalline substance with a melting point of $80--82{ }^{\circ} \mathrm{C}$. It is soluble in water, xylene, chloroform, acetone and ethyl alcohol. The maximum permissible concentration (MPC) in air of the working zone is $2 \mathrm{mg} / \mathrm{m}^{3}$. Working concentration of $1 \mathrm{mg} \mathrm{d.v}$ per $\mathrm{kg}$ of soil. It is 
permitted for dealing with malsekko, anthracnose, tetter and gray mould (standard of the expenditure is 9--12 kgf of d.v./ga), for reduction in losses during storage (including from pit rot) of the sugar beet (10 $\mathrm{g} / \mathrm{t}$ of product/drug) [8].

\section{Methods and Materials}

The models of soil No. 1--3 were undertaken in June, 2018 in the forest-park zone, and No. 4-6 on the lawn near the roadway.

Soil models selected by a sterile knife were put then into pre-prepared glass widenecked sterile jar, which is closed with a plug, wrapped up (a plug) by a sterile cotton. Labels were stuck on the jars with indicating the location from which the sample was taken, horizon and other data.

The topsoil was removed $(2.0 \mathrm{~cm})$ for taking a sample that could be contaminated with extraneous micro-flora. Then, with the use of a scoop we took 100--200 g of soil and poured into a jar.

The pre-sowing preparation of the soil was carried out by sieving, grinding $10 \mathrm{~g}$ of soil hardened to a pasty state in a porcelain mortar and pestle with a rubber tip for spores' desorption and soil particles' mycelium from the surface.

Hinge quantity was transferred into $90 \mathrm{ml}$ of sterile water, got mixed during 15--20 minutes on the rocker. For the desorption of the mycelium and spores from soil particles' surface it has been added the surfactant (pyrophosphate of sodium 0,1\%).

The material preparation was carried out under the sterile conditions, in line with all safety requirements.

To isolate the fungi, solid nutrient media with readily available carbon sources -- the Chapek medium/environment -- were used.

With the help of this nutrient medium, fast-growing and abundantly defensive taxa were found and taken into account.

In order to study the physiological characteristics of nutrition, we used 10 fermentation media differing in the combination of carbon and nitrogen sources. The criterion for assessing the nutritional needs of fungus was biomass accumulation.

In soils, fungi are found in associations with other organisms. Therefore, to inhibit the growth of some concomitant flora, streptomycin and penicillin were added.

The study of samples towards spores of micromycetes (quantitative and qualitative analysis) was performed according to generally accepted methods $[3,4]$. 
Crops were incubated in a thermostat at the temperature of $26{ }^{\circ} \mathrm{C}$ for 7 days, after which they were identified -- a qualitative analysis of mold micro-flora by visual inspection of experimental Petri plates followed by the microscopic examination with an Olympus BX 53 optical microscope. Identification was carried out according to the determinants and mycological atlases [5--7].

The identification of the fungi was based on a comparison of the macroscopic and microscopic features of the studied culture with the previously described features of the fungi well-known. Physiological tests in identification of the fungi are used a little [1].

In our study, we prepared a drug "crushed drop" on glasses.

A drop of water of a physiological solution $(0.5 \% \mathrm{NaCl}$ solution) was applied to the middle of a clean glass slide. The test material was inserted into it with a needle, and then, the material was carefully distributed in suspension [10].

The cover glass was placed on the edge near the drop with microorganisms and gradually lowered, trying to prevent air bubbles from interfering with the microscopy between the glasses. With a handle of the loop we pressed a cover glass to the main one. The excess liquid protruding beyond the edges of the cover glass was removed with a strip of filter paper. The prepared drug was immediately investigated.

In the drug, in a light and dark field, there were established the shape and size of the cells, their physiological state, the nature of reproduction, the location of the spores, the presence of spare nutrients in the cell, and mobility.

Comparison and analysis of the study results was carried out in the Statistical Package for Social Science (IBM SPSS Statistics 23).

We used the Mann-Whitney test to estimate the statistical significance of the differences between samples. The U-criterion is suitable for small samples comparison: in each of the samples there must be at least 3 feature values.

Differences were considered significant when the probability of erroneous acceptance regarding the null-hypothesis about the equality of general means $(p<0.05)$.

\section{Results}

The results of the study are presented in Table 1.

When identifying Aspergillus and Penicillium, a special attention was paid to some cultural characteristics -- the growth rate of the colony, the appearance of the colony, its texture (velvety, fluffy, woolly, rough). In addition, for Aspergillus, the form's characters 
with cleistothecia ascocarp (rounded structure of sexual sporulation, containing bags and ascospores and without an outflow opening). Cleistothecia is clearly visible under a microscope.

The diagnostic sign for Aspergillus and Penicillium is the presence or absence of a column formed with chains of conidia extending from the materials, connection of the conidiophore with the substrate, conidiaform, its surface, and dimensions. In Aspergillus fungi, sections were isolated according to the presence or absence of profialides.

TABLE 1: Mold fungi in soil samples.

\begin{tabular}{|l|c|c|c|c|c|c|}
$\begin{array}{l}\text { No. Soil } \\
\text { sample }\end{array}$ & \multicolumn{5}{|c|}{ Mold fungi, KOE/g of soil } & $\begin{array}{c}\text { Other mold } \\
\text { fungi }\end{array}$ \\
\hline & $\begin{array}{c}\text { Aspergillus } \\
\text { spp. }\end{array}$ & $\begin{array}{c}\text { Penicillium } \\
\text { spp. }\end{array}$ & $\begin{array}{c}\text { Cladosporium } \\
\text { spp. }\end{array}$ & spp. & $\begin{array}{c}\text { Mortierella } \\
\text { spp. }\end{array}$ & \\
\hline 1 & 1246.8 & 3937.9 & 0 & 783.5 & 622.9 & 516.2 \\
\hline 2 & 1738.9 & 10530.7 & 617.5 & 213.8 & 722.4 & 921.7 \\
\hline 3 & 1648,2 & 12428.7 & 611.2 & 356.3 & 783.6 & 250.0 \\
\hline 4 & 8465.2 & 18563.1 & 5014.8 & 211.6 & 0 & 245.0 \\
\hline 5 & 9425.6 & 21675.5 & 4835.6 & 180.4 & 0 & 230.0 \\
\hline 6 & 9748.0 & 20936.1 & 5622.6 & 208.0 & 0 & 251.4 \\
\hline
\end{tabular}

Cladosporium spp. refers to the demacium hyphomycetes. Conidia of these fungi are small. Demacium type -- color from gray to olive, brown or black.

Trichoderma spp. belongs to Monilian hyphomycetes. Moniliy type - color from white to beige or other light colors. Conidia are small.

In species of the genus Mortierella (mortierella), the zygotes are surrounded by a loose interweaving of such appendages, which are often intertwined with branches of the vegetative hyphae, forming a kind of loose wrapper around the zygotes. As a result, a rudimentary fruit body, the zygocarp, is formed.

Samples of the forest-park zone were conditionally assigned to sample 1, and samples from the lawn near the roadway were assighed to sample 2 .

For clarity, the results are presented in Figures 1--5.

As a result of the study, we noted that the KOE Aspergillus spp. prevailed in lawn samples near the roadway.

When studying the morphological properties of isolated strains of Aspergillus spp. it was noted that the vegetative body is represented by a very branched mycelium, penetrating the substrate. Aspergillus spp. Mycelium cells are multi-core. Conidiophore Aspergillus spp. move up from the supporting cells. Conidiophores consisted of a single 


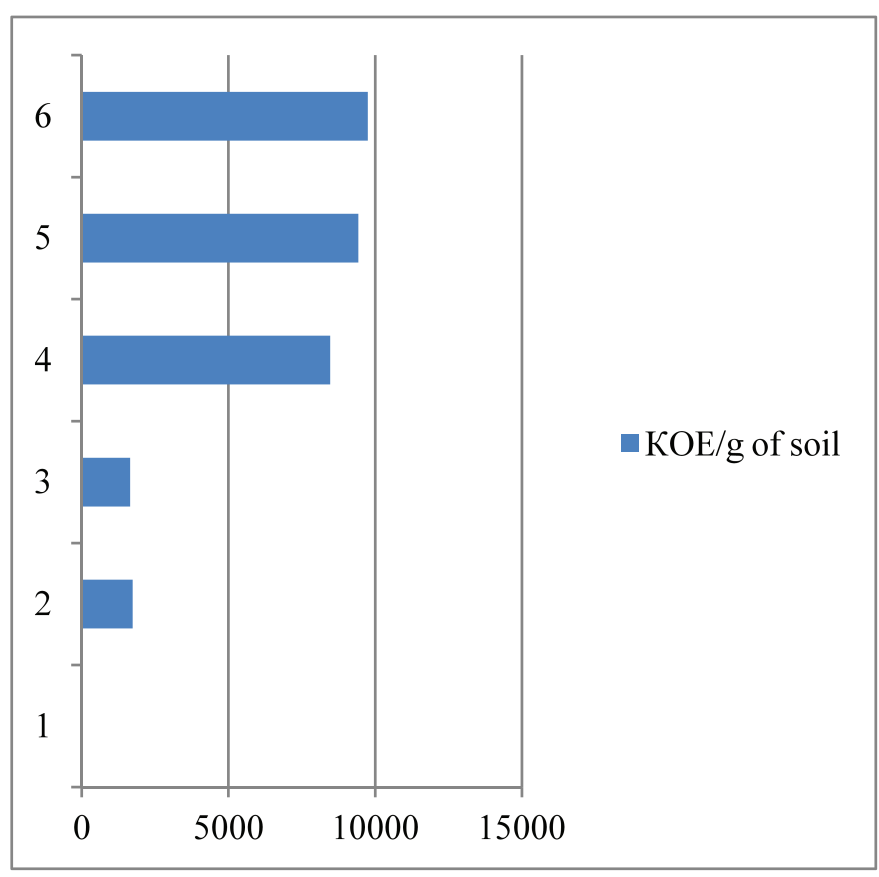

Figure 1: Aspergillus spp. in soil under study.

cell. The conidiophores among the strains under study were colorless, like the mycelium hyphae. Their shells are smooth. The upper part of the conidiophore swells, forming a rounded bladder. Flag-shaped cells are placed on the bladder -- fialida, from a narrow neck of which unicellular conidia are going one after another, in a chain. Directly, at the opening at the top, the conidia filial have a thin shell. The results of the statistical analysis are presented in Tables 2--3.

TABLE 2: Ranks.

\begin{tabular}{|l|c|c|c|}
\hline Groups & N & Medium rank & Sum of ranks \\
\hline 1 & 3 & 2.00 & 6.00 \\
\hline 2 & 3 & 5.00 & 15.00 \\
\hline Total & 6 & & \\
\hline
\end{tabular}

Significance is 0.05 , therefore, there is no statistically significant difference between groups.

TABLE 3: Ranks.

\begin{tabular}{|l|l|c|c|}
\hline Groups & N & Medium rank & Sum of ranks \\
\hline 1 & 3 & 2.00 & 6.00 \\
\hline 2 & 3 & 5.00 & 15.00 \\
\hline Total & 6 & & \\
\hline
\end{tabular}

Significance is 0.05 , therefore, there is no statistically significant difference between groups. 


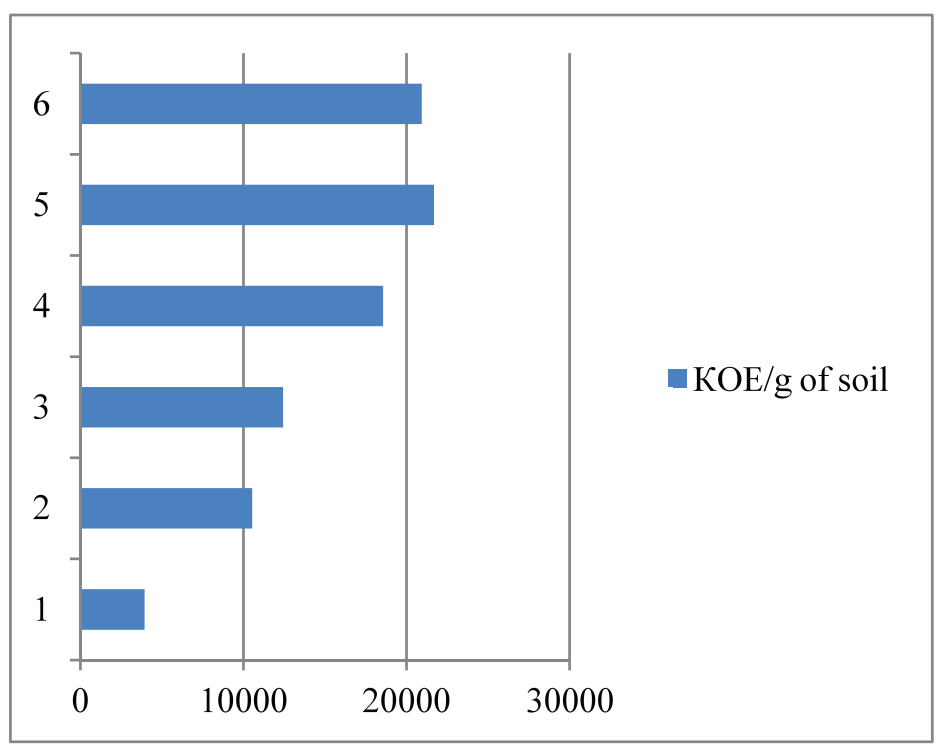

Figure 2: Penicillium spp. in soil under study.

As a result, we noted that the KOE Aspergillus spp. prevailed in lawn samples near the roadway.

When studying the morphological properties of isolated strains of Penicillium spp. it was noted that the mycelium is abundant, completely immersed in agar, forms the dense and thick colonies. Hyphae are improperly branching, septicated, unstained. Conidiophores are formed on the undifferentiated substrate mycelium hyphae, thinwalled. Septidial conidiophores carry at their end a whorl of fialids carrying conidiogenic cells along a whorl. Conidiogenic cells -- fialida -- flasklike. Conidia, which are singlecelled, are formed basipetally on the neck tops of fialids, narrowed in the neck.

The results of statistical analysis are presented in Tables 5--6.

As a result, we noted that the KOE Cladospori spp. prevailed in the lawn samples near the roadway.

When studying the morphological properties of selected strains of Cladosporium spp. it was noted that the studied strains are characterized with a dark-colored mycelium, on which branched chains of blastoconidia are formed. Hyphae are branching, septicated, smooth-walled. Conidiophores are solitary, straight, nodular and near the top they are pigmented. The branching of conidiophores is usually holoblastic. Conidiogenic cells are terminal, cylindrical. Conidia (blastoconidia) are solitary.

The results of the statistical analysis are presented in Tables 4.

When studying the morphological properties of isolated strains of Trichoderma spp. it was noted that the colonies are transparent. Conidiophores are very branched. The 


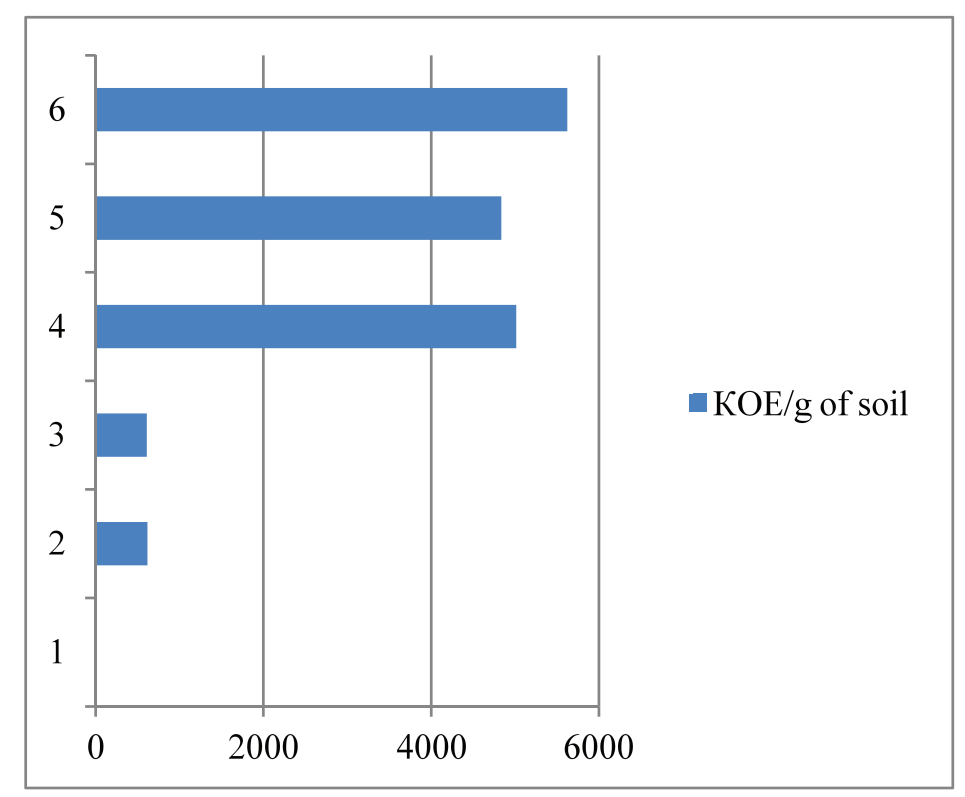

Figure 3: Cladosporium spp. in soil samples under study.

TABLE 4: Ranks.

\begin{tabular}{|l|c|c|c|}
\hline Groups & N & Medium rank & Sum of ranks \\
\hline 1 & 3 & 2.00 & 6.00 \\
\hline 2 & 3 & 5.00 & 15.00 \\
\hline Total & 6 & & \\
\hline
\end{tabular}

Significance is 0.05 , therefore, there is no statistically significant difference between groups.

main branches of conidiophores produce lateral branches that are paired. Conidiophore ends with one or more fialida. Fialida enlarged in the middle. Conidia are smooth.

As a result, we noted that Mortierella spp. were presented only in the samples from the forest- park zone.

When studying the morphological properties of isolated strains of Mortierella spp. it was noted that Mortierella spp. zygotes are surrounded by a loose plexus of appendages, which are often intertwined with branches of the vegetative hyphae, forming a loose wrapper around the zygotes.

The results of the statistical analysis are presented in Tables 5--6.

TABLE 5: Ranks.

\begin{tabular}{|l|l|c|c|}
\hline Groups & N & Medium rank & Sum of ranks \\
\hline 1 & 3 & 5.00 & 15.00 \\
\hline 2 & 3 & 2.00 & 6.00 \\
\hline Total & 6 & & \\
\hline
\end{tabular}

Significance is 0.05 , therefore, there is no statistically significant difference between groups. 


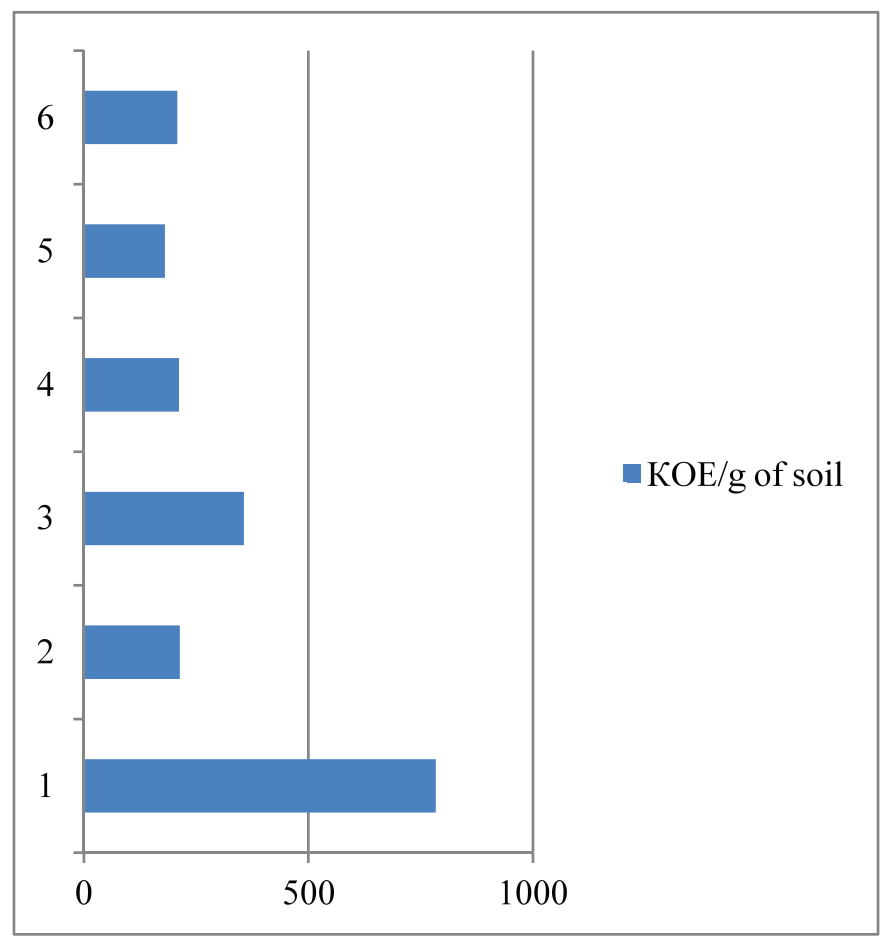

Figure 4: Trichoderma spp. prevailed in samples in the forest-park zone.

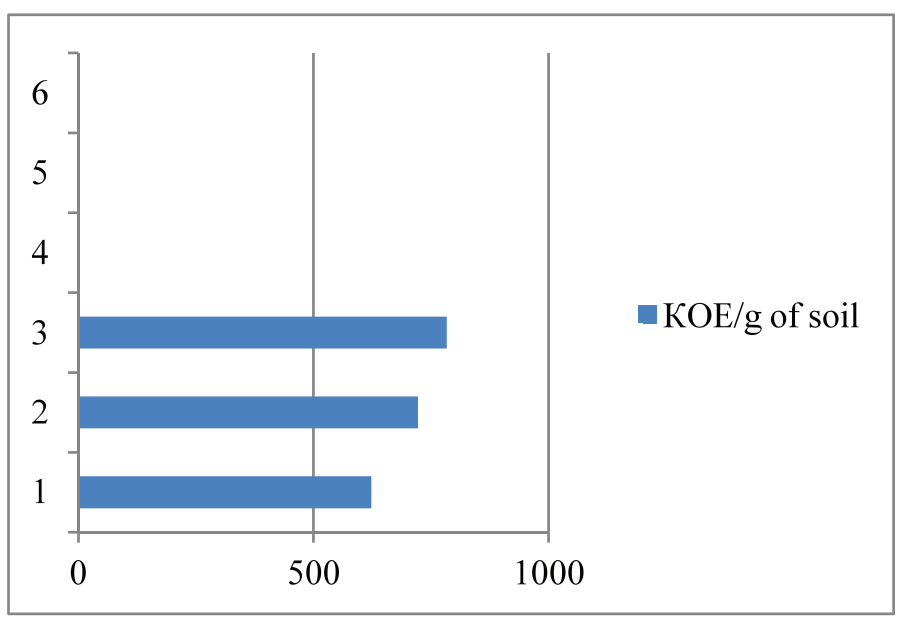

Figure 5: Mortierella spp. in the soil samples.

When studying the physiological characteristics of nutrition, it was found that the accumulation of biomass is individual at the level of the strain. For example, in the strains of Penicillium spp., Mortierella spp., Trichoderma spp., Aspergillus spp. the biomass accumulation is more dependent on the carbon source. The biomass accumulation in the strains of Cladosporium spp. depended very little on nitrogen sources. The strains of Mortierella spp., Trichoderma spp. grew very poorly in the environment containing urea as the single nitrogen source. In some strains, the biomass accumulation proceeded depending on some combinations of carbon and nitrogen sources. 
TABLE 6: Ranks.

\begin{tabular}{|l|c|c|c|}
\hline Groups & N & Medium rank & Sum of ranks \\
\hline 1 & 3 & 5.00 & 15.00 \\
\hline 2 & 3 & 2.00 & 6.00 \\
\hline Total & 6 & & \\
\hline
\end{tabular}

Significance is less than 0.05 , therefore, there is statistically significant difference between groups.

Thus, the microscopic analysis of the fungi grown in solid nutrient environment allowed to identify the micromycetes belonging to the following genera: Penicillium, Aspergillus, Trichoderma, Cladosporium, Mortierella, etc.

Among the selected mold fungi there are conditionally pathogenic, belonging to group IV pathogenicity [8]: Aspergillus spp., Penicillium spp. and Trichoderma spp. At the same time, the samples taken from the lawn near the roadway are more contaminated by mold fungi than in the forest-park zone.

The study allowed us to come to the following

\section{4. conclusions}

1. The microscopic analysis of the fungi grown in solid nutrient environment allowed to identify the micromycetes belonging to the following genera: Penicillium, Aspergillus, Trichoderma, Cladosporium, Mortierella, etc. Among the selected mold fungi there are conditionally pathogenic, belonging to group IV pathogenicity [8]: Aspergillus spp., Penicillium spp. and Trichoderma spp. At the same time, the samples taken from the lawn near the roadway are more contaminated by mold fungi than in the forest-park zone.

2. In addition, we were studying the morphological characteristics of the cells of the studied strains. When studying the physiological characteristics of nutrition, it was found that the accumulation of biomass is individual at the level of the strain.

\section{References}

[1] Eremeeva, S.V. (2009). Mold fungi. Methods of isolation, identification, storage: Reference manual for students of higher educational institutions studying in areas and specialties of environmental, biological and biotechnological profile. Astrakhan: ASTU, 104 p. 
[2] Semerikov, V.V., Chetina, O.A., Balandina, S.Yu., Schwartz, K.G. (2013). On the biodiversity of mold fungi of technogenically altered soils in the Perm Territory. Geographical Bulletin, no. 4(27), pp. 79--81.

[3] Litvinov, M.A. (1969). Methods for studying soil microscopic fungi. Leningrad: Science, $128 \mathrm{p}$.

[4] USSR Pharmacopoeia, 11 ${ }^{\text {th }}$ ed. (1990)...Medicine, vol. 2, $400 \mathrm{p}$.

[5] Bilay, V.I., Kurbatskaya, Z.A. (1990). The determinant of toxic micromycetes. Kiev: Sciences. Dumka, 236 p.

[6] Reillo, A.I. (1950)..Mushrooms of the genus Fusarium. Moscow: Agricultural publishing house,

[7] Sutton, D. (2001). The determinant of pathogenic and opportunistic fungi. Moscow: Mir, $486 \mathrm{p}$.

[8] SP 1.3.2322-08 Safety in working with microorganisms of the III--IV groups of pathogenicity (danger) and pathogens of parasitic diseases. Appendix no. 1 "Classification of microorganisms that cause infectious human diseases, protozoa, and poisons of biological origin by pathogenicity groups".

[9] Babieva, I.P., Zenova, G.M. (1989). Soil biology. Moscow: Izd. Moscow State University, $336 \mathrm{p}$.

[10] Babieva, I.P., Agre, N.S. (1971). A practical guide to soil biology. Moscow: Izd. Moscow State University, $140 \mathrm{p}$.

[11] Workshop on microbiology. Moscow: Academy, 2005, 608 p.

[12] Sutton, D., Fothergill, A., Rinaldi, M. (2001). Determinant of pathogenic and certainly pathogenic fungi. Moscow: Mir, $486 \mathrm{p}$.

[13] Tepper, E.Z., Shil'nikova, V.K., Pereverzeva, G.I. (2004). Workshop on microbiology. Moscow: Drofa, 256 p. 